\title{
Laparoscopic Cholecystectomy: An Early Experience at A Tertiary Care Hospital in Islamabad
}

\author{
Madeeha Subhan Waleed ${ }^{1}$, Waleed Sadiq ${ }^{2}$, Mumtaz Akhtar ${ }^{3}$, Uzzam Ahmed Khawaja ${ }^{4}$ * \\ ${ }^{1}$ Ayub Medical College, Abbottabad, Pakistan. \\ ${ }^{2}$ Staten Island University Hospital, New York, USA. \\ ${ }^{3} \mathrm{Al}$ Nafees Medical College and Hospital, Islamabad, Pakistan. \\ ${ }^{4}$ Jinnah Medical and Dental College, Karachi, Pakistan. \\ *Corresponding Author: Khawaja UA, Jinnah Medical and Dental College, Karachi, Pakistan
}

Received date: 21 September 2020; Accepted date: 15 October 2020; Published date: 21 October 2020

Citation: Waleed MS, Khawaja UA, Akhtar M, Sadiq W (2020) Laparoscopic Cholecystectomy: An Early Experience at A Tertiary Care Hospital in Islamabad.Comm Med Pub Health Rep 1(4): https://doi.org/10.38207/jmcrcs20201053

Copyright: (C) 2020 Waleed MS. This is an open-access article distributed under the terms of the Creative Commons Attribution License, which permitsunrestricted use, distribution, and reproduction in any medium, provided the original author and source are credited.

\begin{abstract}
Background

Gallbladder is an ovate shaped organ lying beneath the liver. Stones can form in the gallbladder and that pathology is known as cholelithiasis. Cholelithiasis is one of the commonest conditions encountered by surgeons all over the world. Laparoscopic Cholecystectomy is a technique in which gallbladder is removed laparoscopically.
\end{abstract}

Keywords: laparoscopic cholecystectomy, gallstones, laparoscopy

\section{Introduction}

Gall bladder removal surgery is termed as cholecystectomy. There are two types: open cholecystectomy and laparoscopic cholecystectomy. Laparoscopic cholecystectomy is the new invasive standard method and is safer and globally accepted [1,2]. Usually, gall stone formation trend tends to increase with age, thus age determining the outcome of this disease [3]. The pioneering surgeon for open cholecystectomy was Carl August Flankerback performing the first-ever open cholecystectomy in 1882 but now it is largely replaced by laparoscopic cholecystectomy that is accepted worldwide [4- 6]. Laparoscopic cholecystectomy is a technique in which the gall bladder is removed via ports that are inserted with minimal manipulation thus improving the time of recovery and markedly decreasing the complication like wound infection $[\mathbf{7 , 8}]$

\section{Methods}

This observational prospective study was undergone in patients of surgical units of Al Nafees Medical Hospital Islamabad during the time of October 2013 to October 2017. Since the year 2013 to 2017 , a total of 445 patients were diagnosed with cases of cholelithiasis on ultrasound. Patients of any age and gender diagnosed with cholelithiasis on ultrasound were included in our study. Patients diagnosed with hepatitis B and hepatitis C and the American Society of Anaesthesiologists (ASA) Physical Status category greater than 4 were excluded from the study.

On admission history of the patient was taken, general physical
Stones in the gallbladder can occur in $10 \%$ to $15 \%$ of the people of the United States and $18.5 \%$ population residing in Europe [9]. In our country like Pakistan the city of Karachi having a population of 21.2 million has cholelithiasis as the third most common indication of admission to the hospital [10]. Gall bladder perforation can occur in 6-40 \% while approximately $13-32 \%$ of patients suffer from complications due to bile spillage [11]. Laparoscopic cholecystectomy is a safe procedure, and the recovery time is very less. Most hospitals have just 23 hours of stay after the procedure and the patient if recovering fine can be discharged on medications [12]. Our study includes 445 patients admitted at Al Nafees hospital Islamabad diagnosed with cholelithiasis undergoing cholecystectomy over a time span of 2014-2017.

examination was done, and investigations were done including Blood Complete picture, Liver function tests, blood sugar random levels, Hepatitis B and C serology and Abdominal Ultrasound. Echocardiogram and Thyroid Junction tester and other investigations were only done in patients with associated conditions.445 patients underwent laparoscopic cholecystectomy for laparoscopic cholecystectomy the four-port technique was applied with pneumoperitoneum created using Verses needle. Data was collected on printed questionaries. All data were then included in the excel sheet. 


\section{Results}

A total of 445 patients were diagnosed with cholelithiasis at Anlages hospital during the years 2014-2017.
The gender distribution was males being 48 (10.78\%) and females being 397 (89.21) as shown in Figure 1.

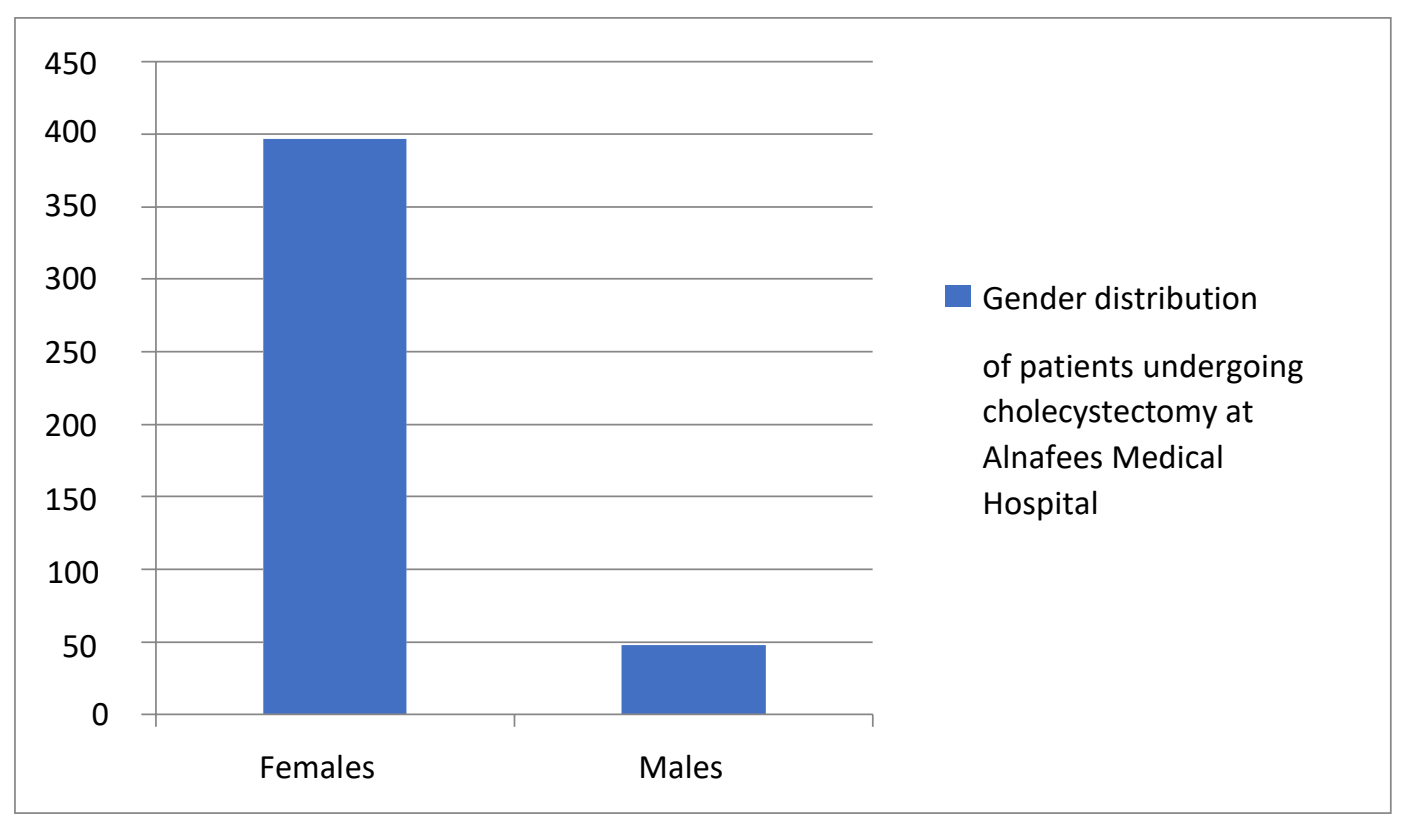

Figure 1: Gender distribution of patients in our study.

The age range was 12 to 75 years and the median age being 32.09 as shown in Figure 2

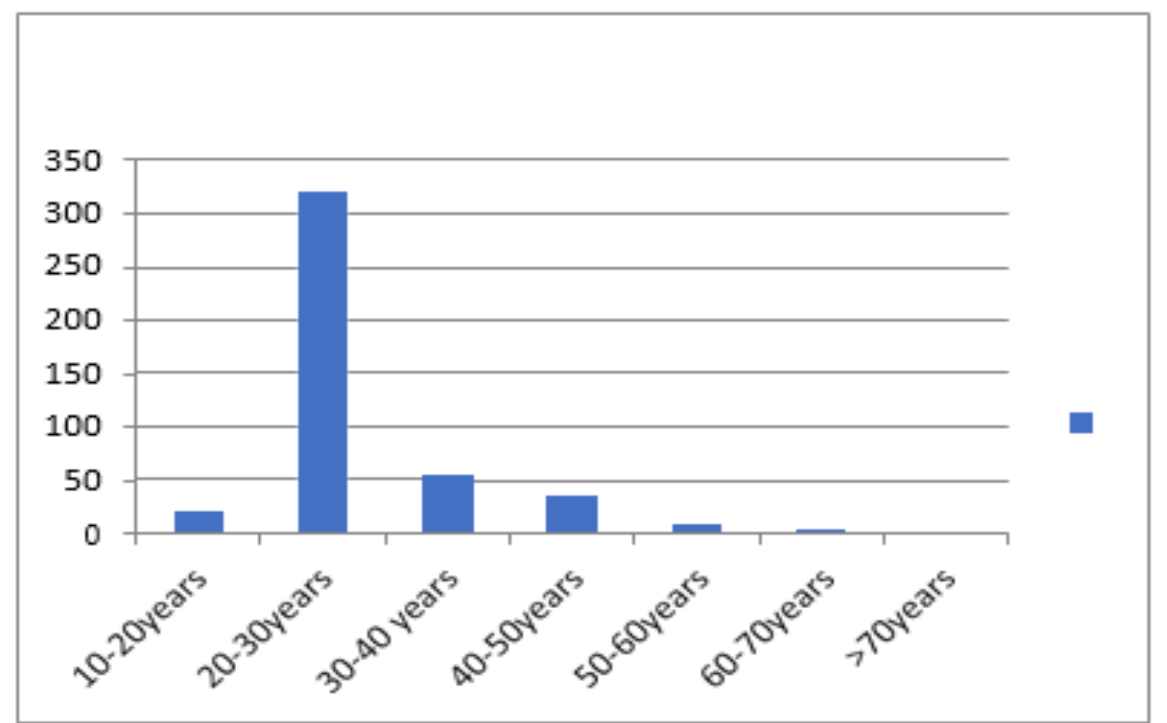

Out of 445 patients that underwent laparoscopic cholecystectomy, patients and 58(13.03\%) underwent laparoscopic converted to open sole laparoscopic cholecystectomy was done in 387(86.96\%) cholecystectomy asshown in Figure 3.

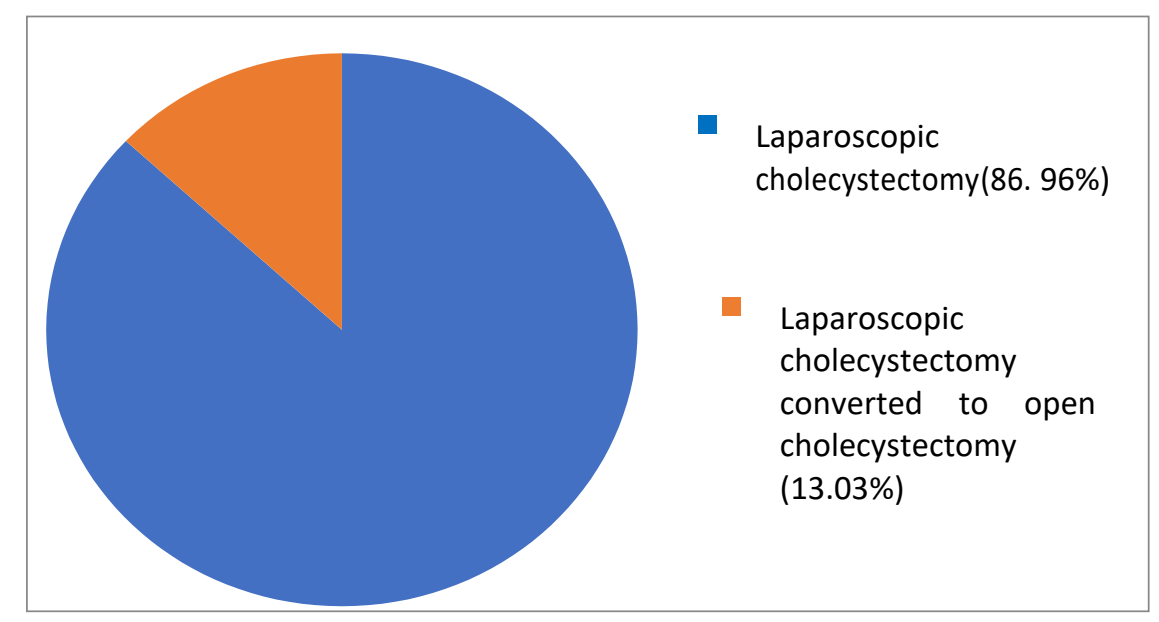

Figure 3: Type of cholecystectomy undergone by the patient.

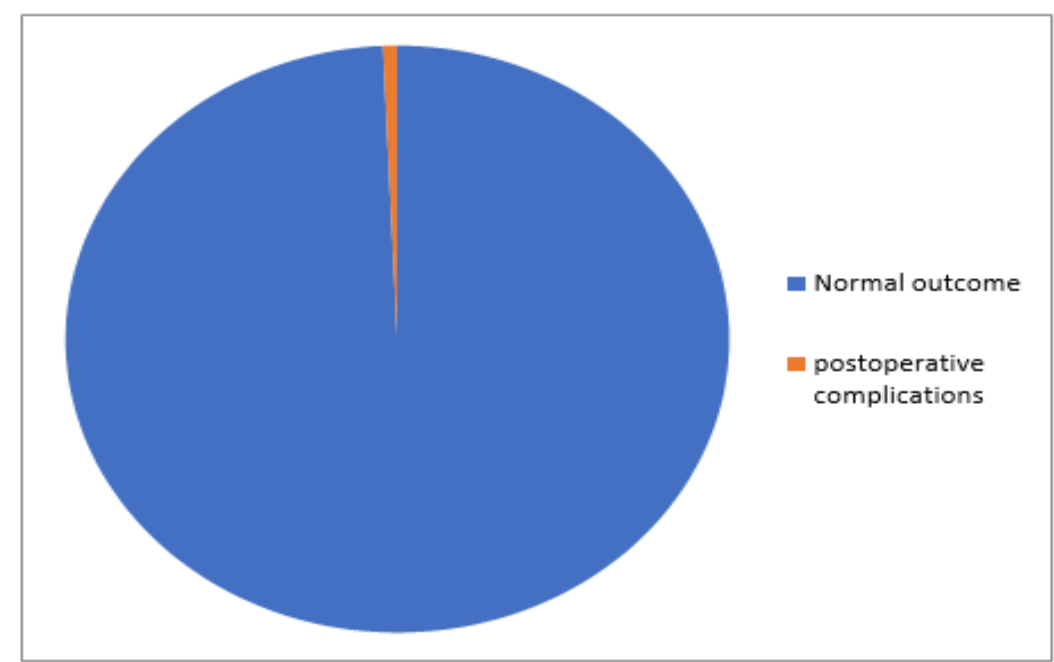




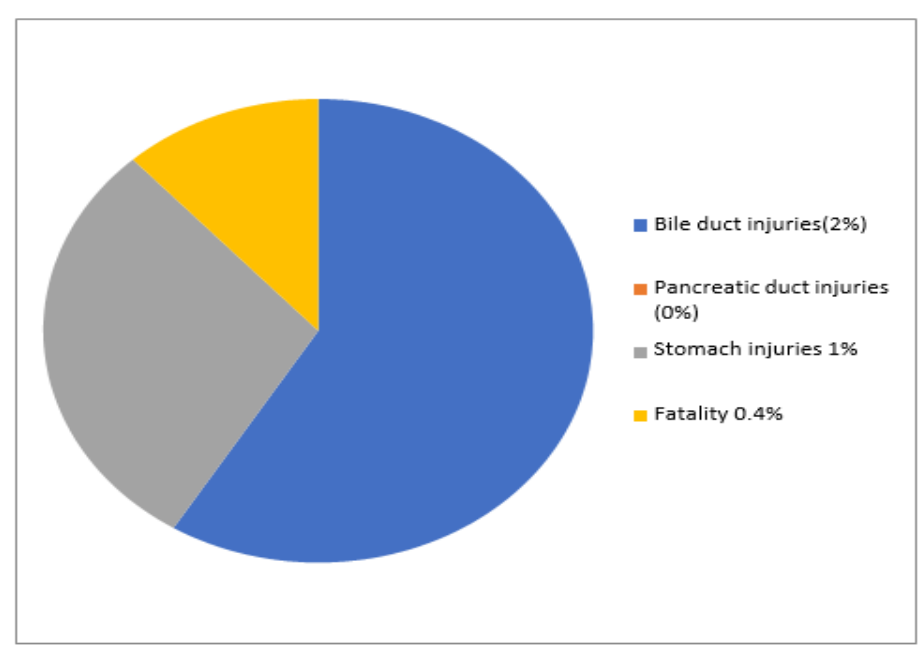

Figure 5: Outcome of the surgery.

$99.3 \%$ of the patients recovered successfully. There was bile duct injury in two patients that was diagnosed postoperatively by MRCP and managed accordingly. Pancreatic duct injury in none, other

\section{Discussion}

In 1882 the first open cholecystectomy was performed and the first laparoscopic cholecystectomywas done in 1987 since then the percentage of laparoscopic cholecystectomy in developed countries are greater than $80 \%$ and in developing In countries like our ratio is lesser due to decreased skilled surgeons and equipment $[13,14]$. In Pakistan, the rate of laparoscopic cholecystectomy is $32 \%$ as reported by Iqbal et al,80 \% by Abasis et al and $21.3 \%$ as reported by Raza et al. [15-18]. Our study had $89.21 \%$ of females that is corresponding to the data in previous literature available that cholelithiasis is far more common in women [19-21]. The conversion rate of laparoscopic cholecystectomy to open cholecystectomy is $13.03 \%$ in our study that is consistent with studies showing that the conversion rate is greater in developing countries [22-24]. Laparoscopic cholecystectomy can lead to operative bile duct injuries during the procedure, a study showing $0.6 \%$ bile duct injuries during laparoscopic cholecystectomy [25].

Two of our patients had bile duct injuries that were then repaired

\section{Conclusion:}

Laparoscopic cholecystectomy is an easy safe and reliable procedure for gall bladder removal with less postoperative complications improving patient is living standard morbidity and time of recovery and improving economy as an early return of patient to work. In a

\section{References}

1. Coccolini F, Catena F, Pisano M, Gheza F, Fagiuoli S, et al. (2015) Open versus laparoscopic cholecystectomy in acute cholecystitis. Systematic review and meta-analysis. Int J Surg 18: 196-204.

2. Ansaloni L, Pisano M, Coccolini F, Peitzmann AB, Fingerhut A, et al. (2016) WSES guidelines on acute calculous cholecystitis. viscera injuries included stomach injuryin one patient. There overall mortality was $0.4 \%$ as shown in Figure 4 \& 5 .

laparoscopically and recovered fine with no complications afterward. Mortality $(0.4 \%)$ in our study was lesser than the mortality rate of (0.7-1.1\%) as quoted by other studies. Aging is a risk factor for mortality with laparoscopic cholecystectomy as well [26, 27]. Port site wound infection occurred in $(0.2 \%)$ patient. Other studies report port site infections to be $2.2 \%$ and $1.63 \%$ [28, 29]. The dressing was done for port site infections and the patients recovered. Injury to the aorta can also occur but in our study, none of the patients had an injury to the aorta or middle colic artery, etc. Dizzier stated 13 cases of aortic injury while Ravago et al stated reported one aortic injury case during cholecystectomy [30, 31]. Now taking into consideration the results of our study laparoscopic cholecystectomy is reliable and safe with lesser postoperative complications and the patients recovering very early. In a resource's deficient country like ours, proper training of the surgeons should be done.

developing country like ours, more surgeons should be trained and should perform laparoscopic cholecystectomy as there are minimum complications of this procedure. 
cholecystectomy. Am J Surg 161(3): 336-338.

5. Terho PM, Leppäniemi AK, Mentula PJ (2016) Laparoscopic cholecystectomy for acute calculous cholecystitis: a retrospective study assessing risk factors for conversion and complications. WorldJ Emerg Surg 11(54).

6. Ji W, Li LT, Li JS (2006) Role of laparoscopic subtotal cholecystectomy in the treatment of complicated cholecystitis. Hepatobilpancreatic Dis Int 5(4): 584-589.

7. Saeed T, Zarin M, Mahmud Aurangzeb, Aziz Wazir, Roohul Muqeem. (2007) Comparative study of Laparoscopic versus open Cholecysyectomy. Pak J Surg Jun 23(2): 96-9.

8. Agrusa A, Romano G, Frazzetta G (2014) "Role and outcomes of laparoscopic cholecystectomy in the elderly," International Journal of Surgery 12(2): 37-39.

9. Schirmer BD, Winters XL, Edlich RF (2005) Cholelethiasis and cholecystitis. J Longterm Eff Med Implants 15(3): 329-338.

10. Jawaid M, Masood Z, Iqbal SA, Sultan T (2004) The pattern of diseases in a Surgical Unit at tertiary care public hospital at Karachi.Pak J Med Sci 20(4): 311-314.

11. Helme S, Samdani T, Sinha P (2009) Complications of spilled gallstones following laparoscopic cholecystectomy a case report andliterature overview. J Med Case Reports 3(1): 8626-8633.

12. Roulin D, Saadi A, Di Mare L, Demartines N, Halkic N (2016) Early Versus Delayed Cholecystectomy for Acute Cholecystitis, Are the 72 hours Still the Rule? A Randomized Trial Ann Surg 264(5):717-722.

13. Tarcoveanu E, Nicculesce D, Georgescu S, Bradea C (2005) Epure O Conversion in Laparoscopic cholecystectomy. Chirugia 100(5): 437-444.

14. Ishiazaki Y, Miwa K, Yoshimoto J (2006) Conversion of laparoscopic to open cholecystectomy between 1993 and 2004. Br JSurg 93(8): 987-991.

15. Iqbal J, Ahmed B, Iqbal Q (2002) Laparoscopic cholecystectomy vs open cholecystectomy, morbidity comparison. The Professional 9(3): 226-234.

16. Abbassi SA, Azami R Haleem A. (2003) An audit of Laparoscopic cholecystectomy performed at PNS Shifa. Pak Armed Forces Med J 53(1): 51-58.

17. Raza M, Wasty WH, Habib L, Farhat J, Saria MS, et al. (2006) An audit of Cholecystectomy. Pak J Surg 23(2): 100-103.

18. Gadaor TR, Talamzii MA (1999) Traditional vs Laparoscopic cholecystectomy. Am J Surg 161: 336-338.

19. Cuschieri A (1999) Laparoscopic cholecystectomy. J R Coll Surg Edinb 44: 187-192.

20. Ji W, Li LT, Li JS (2006) Role of laparoscopic subtotal cholecystectomy in the treatment of complicated cholecystitis. Hepatobilpancreatic Dis Int 5(4): 584-589.

21. Purkayastha S, Tilney HS, Georgiou P, Athanasiou T, Tekkis PP, et al. (2007) Laparoscopic cholecystectomy versus minilaparotomy cholecystectomy: a meta-analysis of randomised control trials.Surg Endosc 21(8): 1294-1300.

22. Iqbal M, Sattar I, Khalid Rasheed, Naqeebullah Khan, Asadullah Khan (2006) Complications of Laparoscopic Cholecystectomy: A Learning Curve. J Surg Pak Dec 11(4): 170-171.

23. Shamim M, Dhari MM, Memon AS (2006) Complications of Laparoscopic cholecystectomy. Pak J Surg 22(2): 70-75.

24. Cheema MA, Zahid MA (2001) An experience of laparoscopic cholecystectomy at Lahore General Hospital. Biomedical 17: 32-36.

25. Viste A, Horn A, Ovrebo K, Christensen B, Angelsen J-H, et al. (2015) Bile duct injuries following laparoscopic cholecystectomy. Scand J Surg 104: 233-237.

26. Wevers KP, Van Westreenen HL, Patijn GA (2013) Laparoscopic cholecystectomy in acute cholecystitis: C-reactive protein level combined with age predicts conversion. Surg Laparosc Endosc Percutan Tech 23: 163-166.

27. Vivek M, Augustine A, and Rao R (2014) "A comprehensive predictive scoring method for difficult laparoscopic cholecystectomy," Journal of Minimal Access Surgery 10(2): 6267.

28. Khan S, Zakiuddin G Oonwala (2007) An audit of Laparoscopic Cholecystectomy. Pak J Surg Jun 23(2): 100-103.

29. Arain GM, Hassan A, Randhawa MH, Malik SA (1998) Laparoscopic Cholecystectomy and its complications: a study of 1100 cases. Pak JGastroentrol 12(1-2): 29-35.

30. Diziel DJ, Milikan KW, Economo SG (1993) Complications of Laparoscopic cholecystectomy, a national survey of 4292 hospitals and an analysis of 77604 cases. Am J Surg 165: 9-14.

31. Roviaro GC, Macioco M, Rebuffat C, Varoli F, Vergani V, et al. (1997) Complications following cholecystectomy. J Roy Coll Surg Edinb 42:324-328 